\title{
Risk of Decline in Upper-Body Function and Symptoms Among Older Breast Cancer Patients
}

\author{
Jennifer L. Westrup, MD, ${ }^{7}$ Timothy L. Lash, DSC, MPH, ${ }^{2,3}$ Soe Soe Thwin, MS, ${ }^{2}$ \\ Rebecca A. Silliman, $M D, P h D^{2,3}$ \\ 'Hematology and Medical Oncology Section, Department of Medicine, Boston University School of Medicine, Boston, MA, USA; \\ ${ }^{2}$ Geriatrics Section, Department of Medicine, Boston University School of Medicine, Boston, MA, USA; ${ }^{3}$ Department of Epidemiology, \\ Boston University School of Public Health, Boston, MA, USA.
}

\begin{abstract}
BACKGROUND: Decline in upper-body function and development of upper-body symptoms are adverse effects of breast cancer therapy and may affect functional independence, particularly among older survivors. The long-term risks and predictors are poorly understood.
\end{abstract}

OBJECTIVE: To characterize the risk of decline in upper-body function and development of symptoms over 4 years of follow-up.

DESIGN: We used a prospective cohort design.

PARTICIPANTS: Six hundred and forty-four early stage breast cancer patients 65 years old or older at surgery enrolled in Rhode Island, North Carolina, Minnesota, and Los Angeles between 1996 and 1999.

MEASUREMENTS: Upper-body function and symptoms were self-reported at baseline, 6,15 months, and annually thereafter to 51 months after surgery.

RESULTS: One half of the participants had a decline in upper-body function and one-quarter developed upper-body symptoms. Breast cancer patients were 5-fold more likely to have a decline in upper-body function over 4 years of follow-up than a similar cohort without breast cancer. Better baseline mental health protected against a decline in upper-body function (odds ratio $[\mathrm{OR}]=0.93,95 \%$ confidence interval [CI] 0.88 to 0.97 for 8 -point higher mental health index). Baseline obesity (OR for body mass index [BMI] $\geq 30 \mathrm{~kg} / \mathrm{m}^{2}$ vs $<30 \mathrm{~kg} / \mathrm{m}^{2}=2.5$, $\mathrm{CI}=1.6$ to 4.0 ) and axillary node dissection (OR for axillary dissection vs not $=3.9, \mathrm{CI}=1.1$ to 14 ) predicted the development of upper-body symptoms.

CONCLUSIONS: Primary care physicians should address upper-body function and symptoms with older breast cancer patients, and inform them that these complications of breast cancer treatment are common.

KEY WORDS: breast neoplasms; complications; therapy.

DOI: $10.1111 / \mathrm{j} .1525-1497.2006 .00384 . \mathrm{x}$

J GEN INTERN MED 2006; 21:327-333.

(C) 2006 by the Authors

$\mathrm{M}$ ore than half of the 200,000 new U.S. breast cancer cases each year are 65 years old or older. ${ }^{1}$ Most (90\%) have nonmetastatic disease, ${ }^{2}$ which has an $84 \%$ 5-year relative survival rate. ${ }^{3}$ The combination of good survival and advances in life expectancy has yielded a pool of 1 million breast cancer survivors over age $65 .^{1}$

Among these survivors, follow-up is best managed by primary care providers in collaboration with oncological specialists. ${ }^{4}$ An important aspect of posttherapy care involves management of treatment-related morbidities, which includes poor upper arm function.

None of the authors have conflict of interest.

Address correspondence and requests for reprints to Dr. Lash: Boston University School of Public Health, 715 Albany St, TE3, Boston, MA 02118 (e-mail: tlash@bu.edu).
Breast surgery, axillary node evaluation, and radiotherapy are mainstays of treatment for breast cancer. ${ }^{5}$ These modalities provide prognostic information and optimize loco-regional control. However, they also have side effects, including functional decline and upper arm symptoms, ${ }^{6-15}$ which may persist for 20 years after initial treatment ${ }^{16}$ and which have particular salience for older women. In older women, functional impairment and sensory symptoms-such as pain, tingling, or numbness-may be amplified by the development of musculoskeletal conditions and comorbidities. ${ }^{17}$ Taken together, these factors may interfere with the ability to maintain functional independence. ${ }^{18}$ We studied a cohort of older women with early stage breast cancer to (a) determine the occurrence of decline in upper-body function and development of upper-body symptoms, and (b) examine the predictors of the occurrence of these outcomes.

\section{METHODS}

\section{Population}

Our procedures have been previously described. ${ }^{19}$ Women diagnosed with breast cancer between December 1996 and September 1999 were identified in Rhode Island, North Carolina, Minnesota, or Los Angeles. We selected women 65 years old or older at diagnosis with stage I disease and a tumor diameter of $1 \mathrm{~cm}$ or greater, stage II or IIIa disease. They had no prior breast cancer and no secondary tumor at another site. Patients were cognitively able to participate, English speaking, and had satisfactory hearing or a proxy respondent ( 21 of 644 baseline interviews were completed by proxies). We obtained permission from the attending physician to contact patients.

We called women who met the entry criteria and sent an enrollment package to explain the study. Those who were not enrolled within 5 months of surgery, or who declined to participate, were excluded. We asked women who agreed to participate to return a signed consent form approved by the institutional review board with oversight at her hospital.

We obtained permission from physicians to contact 1,621 women; 783 consented to full participation, and 82 women consented to medical record review only. The proportion of women whose physicians refused to allow contact increased with age, from $16 \%$ (65 to 69 years old) to $25 \%$ (80 years and older). Similarly, the patient refusal proportion increased with age, from $35 \%$ (65 to 69 years old) to $52 \%$ (80 years and older). ${ }^{19}$

Manuscript received May 29, 2005

Initial editorial decision August 9, 2005

Final acceptance November 29, 2005 


\section{Data Collection}

Enrolled participants completed telephone interviews at 3 to 5 months (baseline, $n=689$ ), 6 to 8 months ( $n=617$ ), 15 to 17 months ( $n=511), 27$ to 29 months ( $n=456), 37$ to 39 months $(n=308)$, and 49 to 51 months $(n=232)$ after surgery. We used the interviews to collect demographic characteristics (age, race, marital status, education), body mass index (BMI in $\mathrm{kg} / \mathrm{m}^{2}$ from reported weight and height), Mental Health Index (MHI-5) and Physical Function Index PFI-10 from the Medical Outcomes Study 36-item short form, ${ }^{20}$ exercises performed after breast cancer therapy, breast cancer treatments (radiation therapy, systemic adjuvant therapies, side of surgery), and dominant handedness. Medical record reviewers collected data on tumor characteristics (AJCC stage ${ }^{21}$ and estrogen receptor status), primary tumor therapy (surgery type and lymph node evaluation), and the Charlson comorbidity index. $^{22}$

\section{Analytic Variables}

Dependent Variables. We assessed upper-body function before diagnosis (baseline interview) and after diagnosis (each interview) based on self-perceived ability to perform 3 tasks: (a) pushing or pulling large objects, such as a living room chair, (b) lifting objects weighing more than 10 pounds, such as a heavy bag of groceries, and (c) reaching or extending arms above shoulder level. ${ }^{23-25}$ For each question, the response options were very difficult, somewhat difficult, or not difficult. Responses at each interview were compared with their prediagnosis levels and women were classified as having a decline in upper-body function if any 2 of the 3 tasks were perceived to be more difficult than they were before diagnosis.

Beginning at the 15-month interview we also assessed upper-body symptoms by asking whether women had the upperbody symptoms of general discomfort and general swelling. Women were asked to grade their symptoms as not at all, a little, a fair amount, much, or very much. Symptomatic women were those who reported these symptoms much or very much.

Independent Variables. Demographic characteristics were age at diagnosis (65 to 69,70 to $79, \geq 80$ years), race (white, nonwhite), marital status (married, widowed, other), education ( $<$ high school, =high school, $>$ high school), and study site (Rhode Island, North Carolina, Minnesota, Los Angeles).

Health status characteristics were the Charlson index $(0,1$, $>1$ ), BMI $\left(\geq 30,<30 \mathrm{~kg} / \mathrm{m}^{2}\right.$ ), mental health (MHI-5, scaled 0 to 100 , higher scores reflect better function), physical function (PFI-10, scaled 0 to 100, higher scores reflect better function), and exercises performed after treatment (not exercising with the upper body, exercising the upper body-but not with exercises recommended by a physician or physical therapist for upper-body function, and exercising the upper bodywith exercises recommended by a physician or physical therapist for upper-body function). Cancer characteristics were AJCC tumor stage (I, IIa, IIb, IIIa); estrogen receptor status (positive, negative, indeterminate), surgery type (mastectomy, breast conserving surgery), radiation therapy (yes, no), and axillary node dissection or sentinel lymph node biopsy (either vs neither; 27 of 549 women [5\%] had a sentinel lymph node biopsy). Surgery on the dominant side was categorized as yes or no.

\section{Analytic Strategy}

We calculated the frequency and proportion of the study population who had each outcome and in each category of the independent variables. All analyses used the initial decline in function or onset of symptoms as the outcome. We calculated the mean and standard deviation of the MHI- 5 and PFI- 10 in the study population. To determine the independent variables strongly associated with the dependent variables, we used the $\chi^{2}$ test for categorical independent variables and the $t$ test for continuous independent variables to calculate a test for homogeneity of proportions or means, respectively. Patient and cancer characteristics associated at the bivariate level with $P<.1$ were entered into logistic regression models (1 for each dependent variable) using generalized estimating equations (GEE) in SAS version $8^{26}$ to mutually adjust the associations. These models were adjusted for age category, enrollment site, and follow-up time (using 5 indicator variables to represent the 6 interviews) regardless of whether they met the entry criterion of $P<.1$.

\section{Population Comparison}

We compared the proportion of breast cancer survivors with upper-body function decline between diagnosis and the 51month interview to the proportion with decline in a subsample of the Framingham Heart Study (FHS) cohort, ${ }^{27}$ frequency matched to our cohort on age, sex, and calendar time, over the 4-year period between examinations 20 and 22. We chose the Framingham cohort for this comparison because we could match on important variables; we had measures on 2 of the 3 upper-body function items; and we were able to follow the cohort for a time period comparable with that of our breast cancer cohort (BC). The prevalence of comorbid diseases at baseline in our $\mathrm{BC}$ was similar to the matched subsample of the FHS cohort: congestive heart failure $(\mathrm{BC}=2 \%, \mathrm{FHS}=1 \%)$; stroke $(\mathrm{BC}=3 \%, \mathrm{FHS}=6 \%)$; peripheral vascular disease $(\mathrm{BC}=1 \%, \mathrm{FHS}=7 \%)$; diabetes mellitus $(\mathrm{BC}=10 \%, \mathrm{FHS}=$ $5.5 \%)$; and chronic pulmonary disease $(\mathrm{BC}=6 \%, \mathrm{FHS}=4 \%)$. Only 2 of the 3 upper-body function measures (push or pull large objects and reach above shoulder level) were available in the Framingham study data, so we defined upper-body function decline as a decline in either of these measures for purposes of this comparison.

\section{RESULTS}

\section{Patient Characteristics}

We excluded 45 women who reported that 2 of the 3 tasks were very difficult before their breast cancer diagnosis, resulting in a final sample of 644 women (Table 1). They were predominantly white (93\%), married (46\%), and had at least a high school education (83\%). About $40 \%$ had 1 or more comorbidity and about $20 \%$ had a BMI of 30 or greater. Eighty-two percent reported exercising after completing treatment as recommended by a doctor or a physical therapist or continuing exercise as part of their lifestyle. Most subjects (81\%) had stage I or IIa disease with estrogen receptor-positive tumors (76\%). They were evenly divided between those receiving mastectomy and breast conserving surgery; half received radiation therapy, and more than $90 \%$ underwent axillary node dissection. Surgery was on the side of the dominant hand in 53\%. 
Table 1. Characteristics of the Study Sample

\begin{tabular}{|c|c|}
\hline & $N(\%)$ \\
\hline \multicolumn{2}{|l|}{ Demographic characteristics } \\
\hline \multicolumn{2}{|l|}{ Age (y) } \\
\hline 65 to 69 & $174(27)$ \\
\hline 70 to 79 & $359(56)$ \\
\hline$\geq 80$ & $111(17)$ \\
\hline \multicolumn{2}{|l|}{ Race } \\
\hline White & $602(93)$ \\
\hline Nonwhite & $41(6.4)$ \\
\hline Missing & 1 \\
\hline \multicolumn{2}{|l|}{ Marital status } \\
\hline Married & $299(46)$ \\
\hline Widowed & 253 (39) \\
\hline Other & $92(15)$ \\
\hline \multicolumn{2}{|l|}{ Education } \\
\hline$<$ High school & $112(17)$ \\
\hline High school & $229(36)$ \\
\hline$>$ High school & $302(47)$ \\
\hline Missing & 1 \\
\hline \multicolumn{2}{|l|}{ Study site } \\
\hline Rhode Island & $160(25)$ \\
\hline North Carolina & $161(25)$ \\
\hline Minnesota & $178(27)$ \\
\hline Los Angeles & $145(22)$ \\
\hline \multicolumn{2}{|l|}{ Health status characteristics } \\
\hline \multicolumn{2}{|c|}{ Comorbidity index (Charlson score) } \\
\hline 0 & $358(56)$ \\
\hline 1 & $233(36)$ \\
\hline$>1$ & $53(8.2)$ \\
\hline \multicolumn{2}{|l|}{ Body mass index $\left(\mathrm{kg} / \mathrm{m}^{2}\right)$} \\
\hline$<30$ & $506(79)$ \\
\hline$\geq 30$ & $136(21)$ \\
\hline Missing & 2 \\
\hline MHI-5* Mean (SD) & $81(16.9$ \\
\hline PFI-10* Mean (SD) & $81.6(22.8$ \\
\hline \multicolumn{2}{|l|}{ Exercise performed } \\
\hline Recommended exercise & $359(62)$ \\
\hline Current exercise & $115(20)$ \\
\hline None & $105(18)$ \\
\hline Missing & 65 \\
\hline \multicolumn{2}{|l|}{ Breast cancer characteristics } \\
\hline \multicolumn{2}{|l|}{ AJCC tumor stage } \\
\hline I & $323(50)$ \\
\hline IIA & $197(31)$ \\
\hline IIB & 98 (15) \\
\hline IIIA & 25 (3.9) \\
\hline \multicolumn{2}{|l|}{ Estrogen receptor status } \\
\hline Positive & $480(76)$ \\
\hline Negative & $81(13)$ \\
\hline Indeterminate & $73(11)$ \\
\hline \multicolumn{2}{|l|}{ Surgery type } \\
\hline Mastectomy & $325(51)$ \\
\hline Breast conserving surgery & 309 (49) \\
\hline Radiation therapy & $319(50)$ \\
\hline Axillary node dissection & $549(91)$ \\
\hline Surgery on dominant side & 343 (53) \\
\hline
\end{tabular}

${ }^{*}$ MHI-5, Mental Health Index and PFI-10, Physical Function Index from the Medical Outcomes Study 36-item short form (MOS SF-36). $\mathrm{SD}$, standard deviation.

\section{Decline in Upper-Body Function}

Three hundred and forty-one women (54\%) reported a decline in upper-body function over the 4 years of follow-up. In the matched sample of the Framingham cohort, 60 of 518 women (10\%) reported a decline in upper-body function over 4 years of follow-up.

Table 2 shows that age, BMI, mental health index, physical function index, exercise performance, node dissection, and surgery on the dominant side were crudely associated with the initial decline in upper-body function. Older age, specifically age 70 to 79 , emerged from the multivariable modeling as a predictor of a decline in upper-body function. A higher baseline mental health index (healthier) appeared to protect against a decline in upper-body function.

\section{Upper-Body Symptoms}

One hundred and nineteen (25\%) of 485 women reported developing new upper-body symptoms over the follow-up. Table 3 shows that BMI, exercise performance, surgery type, and receipt of axillary node dissection were associated crudely with developing upper-body symptoms. Important predictors of developing upper-body symptoms that emerged from the multivariate model were higher BMI and receipt of axillary node dissection.

\section{CONCLUSIONS}

Previous studies have described sensory and functional morbidity arising in women treated for breast cancer. ${ }^{6-15}$ Only 1 addressed the symptomatic and functional consequences in elderly women, and the duration of follow-up was only 24 months. ${ }^{28}$ We followed a large cohort of older women treated for early stage breast cancer for 4 years after primary therapy to identify factors associated with 2 related complications of treatment: decline in upper-body function and development of upper-body symptoms.

Women 70 to 79 years old were more likely to experience upper-body function decline than women 65 to 69. However, women 80 years or older did not experience more symptomatic or functional morbidity than the 65- to 69-year-old reference group. Performance testing of upper-body function would be required to determine whether our findings are a reporting artifact, are because of role differences between the 2 older groups, reflect selection of only the healthiest women in the oldest group, or are true age-related patterns.

Although comorbid conditions have been previously associated with decline in upper function, ${ }^{13,14}$ the relation of comorbid disease to symptoms has not been previously investigated, nor has its relation to function as long as 4 years after treatment. In this study, women with comorbid diseases reported decline in upper-body function and development of symptoms approximately as often as women with no comorbidities. Women with a BMI of 30 or more at baseline were more likely to have upper-body symptoms after treatment, but not functional decline. The association between BMI in the obese range and development of upper-body symptoms has not been previously reported, and has important implications given the growing obesity epidemic.

Receipt of axillary node dissection, compared with clinical evaluation, was more strongly related to symptoms than to decline in function. This difference likely reflects the technique of axillary dissection. The superior trunks of the brachial plexus, which innervate muscles of the upper arm, should not be exposed during surgery, thus preserving power and function. However, the sensory branches of the brachial plexus and the intercostobrachial nerve can be intermingled with nodal tissue and may be sacrificed at surgery, resulting in altered sensation to the arm. The intercostal sensory nerves may also be interrupted, thus altering sensation to the axilla and lateral chest. 
Table 2. Characteristics Associated with Decline in Upper-Body Function After Definitive Surgery for Breast Cancer

\begin{tabular}{|c|c|c|c|}
\hline Variable Categories ( $P$-value for crude test of homogeneity) & $\begin{array}{c}\text { Decline, } \\
N=341(54 \%)\end{array}$ & $\begin{array}{l}\text { No Decline, } \\
N=286(46 \%)\end{array}$ & $\begin{array}{l}\text { Mutually Adjusted Odds Ratio } \\
\text { (95\% confidence interval)* }^{*}\end{array}$ \\
\hline \multicolumn{4}{|l|}{ Age in years $(P=.02)$} \\
\hline$\geq 80$ & $50(15 \%)$ & $57(20 \%)$ & 0.98 (0.63 to 1.5$)$ \\
\hline \multicolumn{4}{|l|}{ Race $(P=.6)$} \\
\hline White & 316 (93\%) & 270 (94\%) & \\
\hline Married & $132(39 \%)$ & 129 (45\%) & \\
\hline Widowed & $44(8 \%)$ & $111(39 \%)$ & \\
\hline Other & $44(8 \%)$ & $46(16 \%)$ & \\
\hline \multicolumn{4}{|l|}{ Education $(P=.8)$} \\
\hline$<$ High school & $58(17 \%)$ & $50(18 \%)$ & \\
\hline High school & $127(37 \%)$ & $98(34 \%)$ & \\
\hline$>$ High school & 156 (46\%) & 137 (48\%) & \\
\hline Minnesota & $94(28 \%)$ & $81(28 \%)$ & $1.1(0.77$ to 1.5$)$ \\
\hline \multicolumn{4}{|l|}{ Charlson comorbidity Index $(P=.16)$} \\
\hline 0 & $171(60 \%)$ & 178 (52\%) & \\
\hline 1 & $95(33 \%)$ & $133(39 \%)$ & \\
\hline$>1$ & $20(7.0 \%)$ & $30(8.8 \%)$ & \\
\hline Body mass index: $\geq 30(P=.6)$ & $68(20 \%)$ & $62(22 \%)$ & \\
\hline MHI-5 ${ }^{\dagger}$ Mean (SD) $(P=.008)$ & $79.9(17.3)$ & $83.5(16.1)$ & $0.93(0.88$ to 0.97$)$ \\
\hline PFI-10 $0^{\dagger}$ Mean $(\mathrm{SD})(P=.08)$ & $80.7(22.7)$ & $83.9(21.9)$ & $0.98(0.95$ to 1.02$)$ \\
\hline \multicolumn{4}{|l|}{ Exercise performed $(P=.005)$} \\
\hline Recommended exercise & $211(67 \%)$ & $138(55 \%)$ & Reference \\
\hline Current exercise & 49 (15\%) & $65(26 \%)$ & $0.80(0.50$ to 1.3$)$ \\
\hline None & $57(18 \%)$ & 46 (19\%) & $1.1(0.80$ to 1.6$)$ \\
\hline \multicolumn{4}{|l|}{ AJCC tumor stage $(P=.9)$} \\
\hline I & $168(49 \%)$ & 146 (51\%) & \\
\hline \multicolumn{4}{|l|}{ Estrogen receptor status $(P=.2)$} \\
\hline Mastectomy & $179(54 \%)$ & $140(49 \%)$ & \\
\hline Radiation therapy $(P=.6)$ & $168(50 \%)$ & $144(52 \%)$ & \\
\hline Axillary node dissection $(P=.08)$ & 297 (93\%) & $240(88 \%)$ & $1.5(0.89$ to 2.4$)$ \\
\hline Surgery on dominant side $(P=.1)$ & $172(50 \%)$ & $162(57 \%)$ & 0.89 (0.67 to 1.2$)$ \\
\hline
\end{tabular}

*Age category, enrollment site, follow-up time, and variables with $\mathrm{P}<.10$ in bivariate analyses were included in the multivariate model.

${ }^{\dagger}$ Mutually adjusted odds ratio for a 8-point change in the index, which is scaled from 0 to 100.

MHI-5, Mental Health Index; PFI, Physical Function Index; SD,standard deviation.

Aspects of breast cancer treatment have been previously associated with upper arm morbidity, including surgical manipulation of the axilla with either sentinel lymph node biopsy or axillary node dissection ${ }^{8,10,29,30}$ and radiation therapy. ${ }^{6,9,13,15,31}$ The advent of less invasive sentinel lymph node evaluation will reduce the prevalence of axillary node dissection among breast cancer patients below that observed in this population, although patients with a positive sentinel node will often still receive an axillary node dissection. Knowledge of the benefits of invasive treatment should be tempered with the risks when counseling patients and patients' preferences should be considered.

Exercise was not strongly related to either decline in function or development of symptoms in our study. Notably, over half of our subjects exercised their upper-body as recommended by a physician or physical therapist to improve or maintain upper-body function. This proportion may be overstated, as we relied on self-report to ascertain exercise status, rather than an intervention, direct observation, or medical record review. The near null association between exercise and decline in function may arise, in part, from a bias toward the null generated by over-reporting of exercise. In addition, the moderate association between prescribed exercises and onset of upperbody symptoms may partly reflect the potential for exercises to be prescribed as treatment for these symptoms, rather than to prevent them.

There are few, albeit encouraging, studies evaluating the potential benefits of posttreatment exercise interventions to mitigate treatment-related effects. ${ }^{32-34}$ A randomized-controlled trial of women with stage I and II breast cancer evaluated outcomes in women who either had usual care (control group), self-directed exercise, or supervised exercise. ${ }^{32}$ A significant 
Table 3. Characteristics Associated with Upper-Body Symptoms After Definitive Surgery for Breast Cancer

\begin{tabular}{|c|c|c|c|}
\hline Variable Categories ( $P$-value for crude test of homogeneity) & $\begin{array}{c}\text { Symptoms, } \\
N=119(25 \%)\end{array}$ & $\begin{array}{c}\text { No Symptoms, } \\
N=366(75 \%)\end{array}$ & $\begin{array}{l}\text { Mutually Adjusted Odds Ratio } \\
\text { ( } 95 \% \text { confidence interval)* }\end{array}$ \\
\hline \multicolumn{4}{|l|}{ Age in years $(P=.5)$} \\
\hline $70-79$ & $70(59 \%)$ & $206(56 \%)$ & $1.2(0.74$ to 2.0$)$ \\
\hline$\geq 80$ & $14(12 \%)$ & $60(16 \%)$ & $1.0(0.51$ to 2.1$)$ \\
\hline \multicolumn{4}{|l|}{ Race $(P=.6)$} \\
\hline White & 115 (97\%) & 346 (95\%) & \\
\hline Married & $69(58 \%)$ & $164(45 \%)$ & \\
\hline Widowed & $42(35 \%)$ & $142(39 \%)$ & \\
\hline Other & $8(7 \%)$ & $60(16 \%)$ & \\
\hline \multicolumn{4}{|l|}{ Education $(P=.2)$} \\
\hline$<$ High school & $25(21 \%)$ & $52(14 \%)$ & \\
\hline High school & $39(33 \%)$ & $125(34 \%)$ & \\
\hline$>$ High school & $55(46 \%)$ & $188(52 \%)$ & \\
\hline Minnesota & $34(29 \%)$ & $102(29 \%)$ & $1.2(0.65$ to 2.4$)$ \\
\hline \multicolumn{4}{|l|}{ Charlson comorbidity Index $(P=.85)$} \\
\hline 0 & $65(55 \%)$ & $210(57 \%)$ & \\
\hline 1 & $44(37 \%)$ & $129(35 \%)$ & \\
\hline$>1$ & $10(8.4 \%)$ & $27(7.3 \%)$ & \\
\hline Body mass index: $\geq 30(P<.001)$ & $41(34 \%)$ & $59(16 \%)$ & $2.5(1.6$ to 4.0$)$ \\
\hline MHI-5 Mean (SD) $(\bar{P}=.15)$ & 79.9 (19.6) & $82.7(15.7)$ & \\
\hline PFI-10 Mean(SD) $(P=.13)$ & $79.2(25.4)$ & $83.2(21.4)$ & \\
\hline \multicolumn{4}{|l|}{ Exercise performed $(P=.03)$} \\
\hline None & $12(10 \%)$ & $74(20 \%)$ & Reference \\
\hline Recommended exercise & $83(70 \%)$ & 216 (59\%) & $1.8(0.83$ to 3.8$)$ \\
\hline Current exercise & $24(20 \%)$ & $76(21 \%)$ & $1.7(0.86$ to 3.3$)$ \\
\hline \multicolumn{4}{|l|}{ AJCC tumor stage $(P=.12)$} \\
\hline I & $51(43 \%)$ & $191(52 \%)$ & \\
\hline Mastectomy & $72(63 \%)$ & $171(47 \%)$ & $1.4(0.86$ to 2.3$)$ \\
\hline Radiation therapy $(P=.9)$ & $59(50 \%)$ & $182(50 \%)$ & \\
\hline Axillary node dissection $(P=.006)$ & $112(97 \%)$ & 307 (89\%) & $3.9(1.1$ to 14$)$ \\
\hline Surgery on dominant side $(P=.9)$ & $65(55 \%)$ & 198 (54\%) & \\
\hline
\end{tabular}

*Age category, enrollment site, follow-up time, and variables with $\mathrm{P}<.10$ in bivariate analyses were included in the multivariate model. SD, standard deviation.

and positive effect on physical functioning was reported in women in the self-directed exercise group and those who were in a supervised exercise group. Moreover, exercise in older women has a multiplicity of positive effects aside from preserving upper-body function. These include improved mood, mobility, and decreased risk of falls. Assuring that a component of exercise is directed at upper-body function among older breast cancer survivors will achieve these positive effects and may also reduce the risk of a decline in upper-body function or the onset of upper-body symptoms secondary to their breast cancer therapy.

There are several limitations that need to be considered when interpreting our results. First, enrollment and exclusion procedures affected the representativeness of the cohort. Older patients were less likely than younger patients to be enrolled. In addition, we excluded women who reported poor upperbody function before diagnosis. These selection forces likely yielded a cohort of older breast cancer survivors that was healthier than nonparticipants. For example, $88 \%$ of women reported exercising after breast cancer treatment or continuing exercise as part of their lifestyle and the mean mental health index and physical function index in our cohort exceeded U.S. norms ${ }^{20}$ for women 65 years old or older (81 vs 62 and 82 vs 75 , respectively). Nonetheless, the associations between the outcome variables and the predictor variables should not be biased by selection into the cohort; it is only their extrapolation to less healthy breast cancer patients that may be affected.

Second, we relied on self-report to ascertain upper-body function and upper-body symptoms. This strategy made our multisite longitudinal study feasible, but precluded the use of performance testing as the gold standard measure of upperbody function. Ascertainment of decline in function is of particular concern, because we asked women to recall their up- 
per-body function before their treatment, and then compared their concurrent self-reported function to the prediagnosis function as a measure of upper-body function decline. If women tended to overstate their prediagnosis function, then this method may overestimate the risk of decline in upper-body function. We do not, however, expect the misclassification to depend on any of the predictor variables, and nondifferential misclassification of upper-body function would bias the estimated associations toward the null on average. Furthermore, patients' self-reports of arm function may be more accurate than objective measures. ${ }^{35-37}$ Objective measures of function do not measure patients' perceptions of their function, and if perceived function is more closely related to quality of life and ability to maintain independence, it may be the more salient measure.

We also used self-report to ascertain the occurrence of upper-body symptoms, and defined the presence of upperbody symptoms only if responses were in the much and very much categories, which may have led to an underestimation of the risk of upper-body symptoms. Upper-body symptoms defined less conservatively may be associated with a different set of predictors. In general, outcome definitions that permit the fewest false positives should yield the strongest and least biased estimates of association, ${ }^{38}$ therefore we chose to implement a strict definition. Finally, we do not have unbiased estimates of the extent to which women recovered function and/or experienced reduced symptoms. In a previous study, we found that seeing a breast cancer specialist in the previous 6 months was the only factor associated with functional recovery $(1,818)$.

With these limitations in mind, we observed that breast cancer survivors reported decline in upper body function 5-fold more often than a matched sample of the FHS cohort, suggesting that decline in upper-body function and development of upper-body symptoms are long-term complications of treatment for early stage breast cancer that have particular importance to older women. We recommend that primary care physicians consider risk stratifying their patients, as older patients and those with lower baseline mental health index are at risk for decline in upper body function, and those with increased BMI and axillary lymph node dissection are at risk for developing upper body symptoms. In following breast cancer survivors, primary care providers should combine a focused review of systems and a targeted examination to assess upperbody function and symptoms. Additional research should identify effective interventions that reduce upper-body symptoms and maintain function among older breast cancer survivors.

The authors thank Dr. Ram Miller for performing the analyses in the FHS cohort. Data collection and analyses were supported by grants R01 CA/AG70818 from the National Cancer Institute and National Institute on Aging and RO1 CA84506 from the National Cancer Institute. Dr. Lash was supported, in part, by K07 CA87724 from the National Cancer Institute. Dr. Silliman was supported, in part, by K05 CA92395 from the National Cancer Institute.

\section{REFERENCES}

1. Lash TL, Silliman RA. Prevalence of cancer (letter). J Natl Cancer Inst. 1998;90:399-400.
2. Satariano WA, Ragland DR. The effect of comorbidity on 3-year survival of women with primary breast cancer. Ann Intern Med. 1994;120:10410.

3. American Cancer Society: Breast Cancer Facts and Figures 2004. 2004.

4. Worster A, Wood ML, McWhinney IR, Bass MJ. Who provides follow-up care for patients with early breast cancer? Can Fam Physician. 1995;41:1314-20.

5. Hughes KS, Schnaper LA, Berry D, et al. Lumpectomy plus tamoxifen with or without irradiation in women 70 years of age or older with early breast cancer. N Engl J Med. 2004;351:971-7.

6. Kwan W, Jackson J, Weir LM, Dingee C, McGregor G, Olivotto IA. Chronic arm morbidity after curative breast cancer treatment: prevalence and impact on quality of life. J Clin Oncol. 2002;20:4242-8.

7. Hack TF, Cohen L, Katz J, Robson LS, Goss P. Physical and psychological morbidity after axillary lymph node dissection for breast cancer. $J$ Clin Oncol. 1999;17:143-9.

8. Rietman JS, Dijkstra PU, Geertzen JH. Short-term morbidity of the upper limb after sentinel lymph node biopsy or axillary lymph node dissection for stage I or II breast cancer. Cancer. 2003;98:690-6.

9. Yap KL, Yuan T, Mal TK, Vogel HJ, Ikura M. Factors influencing arm and axillary symptoms after treatment for node negative breast carcinoma. Cancer. 2003;97:1369-75.

10. Temple LK, Baron R, Cody HS III, et al. Sensory morbidity after sentinel lymph node biopsy and axillary dissection: a prospective study of 233 women. Ann Surg Oncol. 2002;9:654-62.

11. Kuehn T, Klauss W, Darsow M, et al. Long-term morbidity following axillary dissection in breast cancer patients-clinical assessment, significance for life quality and the impact of demographic, oncologic and therapeutic factors. Breast Cancer Res Treat. 2000;64:275-86.

12. Warmuth MA, Bowen G, Prosnitz LR, et al. Complications of axillary lymph node dissection for carcinoma of the breast: a report based on a patient survey. Cancer. 1998;83:1362-8.

13. Lash TL, Silliman RA. Patient characteristics and treatments associated with a decline in upper-body function following breast cancer therapy. J Clin Epidemiol. 2000;53:615-22.

14. Silliman RA, Prout MN, Field T, Kalish SC, Colton T. Risk factors for a decline in upper-body function following treatment for early stage breast cancer. Breast Cancer Res Treat. 1999;54:25-30.

15. Ververs JM, Roumen RM, Vingerhoets AJ, et al. Risk, severity and predictors of physical and psychological morbidity after axillary lymph node dissection for breast cancer. Eur J Cancer. 2001;37:991-9.

16. Kornblith AB, Herndon JE II, Weiss RB, et al. Long-term adjustment of survivors of early-stage breast carcinoma, 20 years after adjuvant chemotherapy. Cancer. 2003;98:679-89.

17. Fried LP, Ferrucci L, Darer J, Williamson JD, Anderson G. Untangling the concepts of disability, frailty, and comorbidity: implications for improved targeting and care. J Gerontol A Biol Sci Med Sci. 2004;59:25563.

18. Lash TL, Silliman RA. Long-term follow-up of upper-body function among breast cancer survivors. Breast J. 2002;8:28-33.

19. Silliman RA, Guadagnoli E, Rakowski W, et al. Adjuvant tamoxifen prescription in women 65 years and older with primary breast cancer. $J$ Clin Oncol. 2002;20:2680-8.

20. Ware J. SF-36 Health Survey, Manual and Interpretation Guide. Boston, MA: The Health Institute; 1993.

21. Fleming ID, Cooper JS, Henson DE, et al. AJCC Cancer Staging Manual. 5th edn. Philadelphia: Lippincott Williams \& Wilkins; 1997.

22. Charlson ME, Pompei P, Ales KL, Mackenzie CR. A new method of classifying prognostic comorbidity in longitudinal studies: development and validation. J Chronic Dis. 1987;40:373-83.

23. Satariano WA, Ragheb NE, Branch LG, Swanson GM. Difficulties in physical functioning reported by middle-aged and elderly women with breast cancer: a case-control comparison. J Gerontol. 1990;45: M3-11.

24. Jette AM, Branch LG, Wentzel RA, Carney WF, Dennis DL, Heist MM. Home care service diversification: a pilot investigation. Gerontologist. 1981;21:572-9.

25. Nagi SZ. An epidemiology of disability among adults in the United States. Milbank Mem Fund 3 Health Soc. 1976;54:439-67.

26. SAS [computer program]. Version 8. Cary (NC): The SAS Institute; 1999.

27. Zhang Y, Niu J, Kelly-Hayes M, Chaisson CE, Aliabadi P, Felson DT. Prevalence of symptomatic hand osteoarthritis and its impact on functional status among the elderly. Am J Epidemiol. 2002;156:1021-7. 
28. Mandelblatt JS, Edge SB, Meropol NJ, et al. Sequelae of axillary lymph node dissection in older women with stage 1 and 2 breast carcinoma. Cancer. 2002;95:2445-54.

29. Schijven MP, Vingerhoets AJ, Rutten HJ, et al. Comparison of morbidity between axillary lymph node dissection and sentinel node biopsy. Eur J Surg Oncol. 2003;29:341-50.

30. Jani AB, Basu A, Heimann R, Hellman S. Sentinel lymph node versus axillary lymph node dissection for early-stage breast carcinoma: a comparison using a utility-adjusted number needed to treat analysis. Cancer. 2003;97:359-66.

31. Herd-Smith A, Russo A, Muraca MG, Del Turco MR, Cardona G. Prognostic factors for lymphedema after primary treatment of breast carcinoma. Cancer. 2001;92:1783-7.

32. Segal R, Evans W, Johnson D, et al. Structured exercise improves physical functioning in women with stages I and II breast cancer: results of a randomized controlled trial. J Clin Oncol. 2001;19:65765.
33. McKenzie DC, Kalda AL. Effect of upper extremity exercise on secondary lymphedema in breast cancer patients: a pilot study. J Clin Oncol. 2003;21:463-6.

34. Burnham TR, Wilcox A. Effects of exercise on physiological and psychological variables in cancer survivors. Med Sci Sports Exerc. 2002;34:1863-7.

35. Segerstrom K, Bjerle P, Nystrom A. Importance of time in assessing arm and hand function after treatment of breast cancer. Scand J Plast Reconstr Hand Surg. 1991;25:241-4.

36. Swedborg I, Borg G, Sarnelid M. Somatic sensation and discomfort in the arm of post-mastectomy patients. Scand J Rehab Med. 1981;13:23-9.

37. Watson TA, Bond AF, Phillips AJ. Swelling and dysfunction of the upper limb following radical mastectomy. Surg Gynecol Obstet. 1963;108:99104.

38. Brenner H, Savitz DA. The effects of sensitivity and specificity of case selection on validity, sample size, precision, and power in hospital-based case-control studies. Am J Epidemiol. 1990;132:181-92. 